\title{
Micro- and Nanoplastic Pollution of Freshwater and Wastewater Treatment Systems
}

\author{
Reina M. Blair ${ }^{1}$ (I) $\cdot$ Susan Waldron $^{1} \cdot$ Vernon Phoenix $^{2} \cdot$ Caroline Gauchotte-Lindsay $^{3}$
}

Received: 15 December 2016/Accepted: 9 May 2017/Published online: 7 June 2017

(c) The Author(s) 2017. This article is an open access publication

\begin{abstract}
Plastic waste is a widespread and persistent global challenge with negative impacts on the environment, economy, human health and aesthetics. Plastic pollution has been a focus of environmental research over the past few decades, particularly in relation to macroplastics that are easily visible by the naked eye. More recently, smaller plastic waste at the micro- and nanoscale has become of increasing concern, resulting in extensive investment in research to advance knowledge on the sources, distribution, fate and impact of these materials in aquatic systems. However, owing to their small sizes and a lack of unified methods, adequate quantitative and qualitative assessment has been difficult. Furthermore, most of the microplastic surveys available to date have focussed in the marine environment while scarce knowledge exists of freshwater systems. Because the majority of marine debris originates on land, the role of wastewater treatment systems and natural fluvial vectors in delivering these emerging contaminants to the environment should be explored. Considering fundamental aspects pertaining to
\end{abstract}

Endorsed by Susan Waldron.

Electronic supplementary material The online version of this article (doi:10.1007/s40362-017-0044-7) contains supplementary material, which is available to authorized users.

Reina M. Blair

r.blair.1@research.gla.ac.uk

1 School of Geographical and Earth Sciences, University of Glasgow, Glasgow, UK

2 Department of Civil and Environmental Engineering, University of Strathclyde, Glasgow, UK

3 School of Engineering, University of Glasgow, Rankine Building, Glasgow, UK microplastic sources, distribution, mobility and degradation in these systems is crucial for developing effective control measures and strategies to mitigate the discharge of these particles to the sea.

Keywords Plastic pollution - Microplastic - Freshwater . Wastewater $\cdot$ Nanoplastic $\cdot$ Emerging contaminants

\section{Introduction}

Plastic waste is pervasive and increasing in land and water environments globally. The 2013 global plastic production was estimated to be 299 million tonnes, a $3.9 \%$ increase from 2012 [77]. Germany and the United Kingdom (UK) are the two highest producers of plastic waste in the European Union (EU), recovering 80 and $26 \%$ of it, respectively [46]. Most plastic in the environment is nonbiodegradable and remains as waste for a long time [29], with approximately $10 \%$ ending up in the oceans [90]. Plastics are lightweight and buoyant, and easily transported long distances across a wide range of environments [15], rendering them ubiquitous contaminants. Previous research from shoreline and beach surveys across all continents indicates that plastic waste commonly accounts for $50-90 \%$ of all marine litter [21]. About $80 \%$ originates from land-based sources [2, 15, 41], suggesting fluvial systems are important transport routes of these contaminants to the sea. However, compared to marine systems, data for freshwaters remain limited, and the magnitude of their impact has yet to be assessed [24].

The emphasis on plastic pollution research in oceans until recently may be because its accumulation and impacts appeared to be more evident in these environments [84]. For example, patches of accumulated floating macroplastic 
debris were observed in gyres and convergence areas in oceans over a decade ago $[28,68,84]$. Furthermore, the marked mechanical effects of plastic litter on marine biota due to entanglement and ingestion raised concerns of its potential harm to biodiversity and ecosystems [21, 84, 92]. While oceans have been used as waste dumps for years despite global efforts to prevent this [44], the majority of plastic litter is produced inland, thus examining its transport to marine environments by rivers may allow for identification and regulation of its main sources [22, 84].

At present, the increased awareness of the growing production and accumulation of plastic pollution in the environment has brought greater focus to the need for development of policies and management strategies. For example, the United Nations Environment Programme (UNEP) called for an urgent need to address plastic pollution of oceans through implementation and enforcement of coordinated strategies, effective policies and regulations, campaigns, and other incentives at national, regional and global levels [52]. The European Marine Strategy Framework Directive (MSFD) 2008/56/EC emphasised the need for more data on the amount, distribution and composition of plastic debris $[38,85]$. However, despite the extensive research devoted to monitoring plastic debris over the past decades, the full extent of its quantity, distribution and impact remains widely unknown. Thus, controlling plastic waste may be confounded by lack of measurement of the extent and thus understanding of source and impact, rather than strategy [15]. Further, the importance of plastic fragments at the micro- and nanoscale has only recently been recognised, and method development to define and measure them is still under way. Microplastics and nanomaterials have been classified by Scotland's Centre of Expertise for Waters (CREW) as emerging contaminants, or alternatively, "contaminants of emerging concern" (CEC) for Scottish watercourses, due to their toxic characteristics and the lack of adequate data for reliable risk assessment [46]. Therefore, it is essential to refine the initial estimates of plastic debris in oceans and inland waters to include these smaller and "invisible" fractions, and identify their main sources before further actions or regulations be implemented.

The concepts of micro- and nano-sized plastics as emerging contaminants, and the role of wastewater and freshwater systems as sinks or sources of these materials to the environment provides the focus for this review. This review synthesises the theory and literature relevant to the topic of micro- and nanoplastic pollution in freshwaters and wastewater systems, including methods for their examination, and identifies knowledge gaps and areas where further investigation are needed.

\section{Micro- and Nanoplastics}

Plastic litter can occur in a wide range of sizes. The literature commonly distinguishes between two broad classes of plastics: macroplastic $(>5 \mathrm{~mm})$ and microplastic $(<5 \mathrm{~mm})[4,31,42,92]$, but different terms and size ranges have been used across studies (Table 1). A unified lower limit for measurement for microplastics has not been defined, but for practical purposes $333 \mu \mathrm{m}(\sim 0.3 \mathrm{~mm})$ is often used when sampling with neuston nets [4, 83]. Nevertheless, because a lower cut-off has not been established, the term microplastic has often been used to encompass pieces ranging from millimetre to nanometre dimensions. More recently, the term "nanoplastic" has been introduced as a separate category [7, 56, 94]. This size class has been defined as particles smaller than $0.2 \mathrm{~mm}$ based on the WG-GES size classification [94], and, smaller than $100 \mathrm{~nm}$ according to the general definition used for nanomaterials [56]. Mostly, nanoplastics have been overlooked in the literature and are the least-studied size class, as evidenced by a lack of discussion of its definition and quantification. Nevertheless, it has been suggested that these nanoscopic plastics may be the most hazardous yet due to their high potential for bioaccumulation and biomagnification [56, 76], thus requiring further investigation. For purposes of this review, for ease of reference the rest of the discussion will focus on micro- and nanoplastics (MNP) jointly as one single size class.

\section{Sources}

Micro- and nanoplastics are classified into two general categories according to source: primary and secondary. Their source of origin determines their shape and composition. Primary MNP are intentionally manufactured in small sizes for different applications, including personal care and cleaning products, and pre-production pellets for fabrication of other plastic goods [4, 83, 84, 87, 91]. The manufacture of primary nanoplastics will likely increase with their use in electronic devices, medicines, cars and airplanes [83]. Primary MNP are likely to be collected mostly intact in industrial and household sewage, and go through wastewater treatment (WWT) facilities before being discharged into the aquatic environment [83]. Secondary MNP originate from the breakdown of larger plastic pieces due to weathering by UV-radiation and physical defragmentation by mechanical forces $[4,16,91]$. Thus, macroplastics will breakdown into microplastics, and these will further break down into nanoplastics. Their abundance and production rates will depend on environmental characteristics and polymer type [4, 23, 84, 91, 95], making 
Table 1 Size class definition of aquatic plastic debris used by various authors

\begin{tabular}{|c|c|c|c|}
\hline Prefix & Size class & Size range & Source \\
\hline \multirow[t]{3}{*}{ Nano } & Nano, micro, millimetre (NMM) & Not available & [7] (abstract) \\
\hline & Nanoplastic & $<0.2 \mathrm{~mm}$ & [94] \\
\hline & & $<100 \mathrm{~nm}$ & {$[56]$} \\
\hline \multirow[t]{13}{*}{ Micro } & Microlitter & $\sim 0.06$ to $0.5 \mathrm{~mm}$ & {$[45]$} \\
\hline & Microplastic & $<0.5 \mathrm{~mm}$ & [91] \\
\hline & & & {$[33]$} \\
\hline & & & [48] (abstract) \\
\hline & & & {$[86]$} \\
\hline & & & {$[18]$} \\
\hline & & $0.333-5 \mathrm{~mm}$ & {$[4]$} \\
\hline & Micro debris & $<2 \mathrm{~mm}$ & {$[57]$} \\
\hline & Small microplastic & $<1 \mathrm{~mm}$ & [93] \\
\hline & & $0.2-1 \mathrm{~mm}$ & {$[71]$} \\
\hline & & $>0.3 \mathrm{~mm}(<1 \mathrm{~mm})$ & {$[32]$} \\
\hline & Large microplastic & $1-5 \mathrm{~mm}$ & [71] \\
\hline & & & {$[32]$} \\
\hline \multirow[t]{4}{*}{ Meso } & Mesolitter & $>0.5 \mathrm{~mm}$ & {$[45]$} \\
\hline & & $5-25 \mathrm{~mm}$ & {$[71]$} \\
\hline & Meso debris & $2-20 \mathrm{~mm}$ & {$[57]$} \\
\hline & & $>5 \mathrm{~mm}$ & {$[86]$} \\
\hline \multirow[t]{3}{*}{ Macro } & Macroplastic/macro debris & $>25 \mathrm{~mm}$ & {$[71]$} \\
\hline & & $20 \mathrm{~mm}$ & [86] \\
\hline & & $>5 \mathrm{~mm}$ & {$[32]$} \\
\hline Mega & Mega debris & $100 \mathrm{~mm}$ & [86] \\
\hline
\end{tabular}

secondary MNP input to oceans harder to trace, quantify and control than primary sources.

Chemical composition, size and surface features of MNP can provide insight to their origins. For example, primary MNP found in personal care products tend to be smaller than $0.3 \mathrm{~mm}$, contain additives (e.g. plasticisers), and are composed mainly of polyethylene (PE), but also may contain polypropylene (PP), polyethylene terephthalate (PET), polymethyl methacrylate (PMMA) and Teflon (PTFE) [83, 87]. Primary MNP in the form of pre-production pellets will be mainly spherical or cylindrical around $5 \mathrm{~mm}$ in size [42]. The polymers PE, PP, and polystyrene (PS) are often used in packaging and thus are indicative of urban origins, while denser polymers like polyvinyl chloride (PVC) and polyester (PES) are commonly used in construction and textiles, respectively [42]. These plastics will be introduced as secondary MNP fragments and fibres from sewage effluent or surface runoff [85]. Currently, there are no data in the literature on the relative abundances of primary to secondary MNP, and only a couple of studies have examined the relationship between fragments of different sizes [58, 59]. Thus, there is a need to address these knowledge gaps for accurate quantification of MNP fractions, assessment of the relationship among abundances of different size classes, and application of precise source characterisation approaches for understanding the potential contributions of different urban and industrial sources [58]. This information is crucial for managing this problem and informing policy, since it is predicted that even if land-based inputs are controlled, plastic debris densities in oceans will continue to increase from secondary sources [24].

\section{Microplastics in Freshwater Environments}

Microplastics were described in the literature as early as the 1960s and 1970s [42], but it was not until 2004 that the term became widely used [91]. Although plastic litter is not a new problem, only recently have MNP become a focus of the scientific community with publications on the topic increasing rapidly [31, 42], particularly in marine systems (see reviews by Andrady et al. [2] and Cole et al. [16]). Data on MNP pollution of continental freshwaters are less abundant than for marine systems (Fig. 1) [24, 92, 94], but the number of publications are also increasing, mostly 
since 2014. The research published between 2011 and 2014 on microplastics in freshwater bodies in Asia, Europe, and North America has been reviewed [24], and additional studies of American, Asian, European, and African sites have been published in 2015 and 2016. All surveys report the presence of different size classes of plastics in these environments and, where available, high relative abundances of MNP compared to macroplastics, in both sediment and surface waters.

In America, most research has concentrated in Canada and the USA, (Fig. 2; Online Resource 1), particularly in the Great Lakes area $[6,18,26,80,96,97]$, including the St. Lawrence River watershed [12]. Of these, only two studies collected data from freshwater bottom sediments [12, 18], and one considered open-water loading (the Laurentian Great Lakes system) [26]. The rest of the studies focussed on lakeshore surveys. Across these studies, microplastics were present in both sediment and surface waters, in higher densities compared to macroplastics, and with a high predominance of pellets and fragments, indicative of contributions from both primary and secondary sources. In addition, microbeads found in the St. Lawrence River were comparable in size, shape and composition to those found in the Laurentian Great Lakes [12], indicating a possible transport of these materials from the municipalities along the river to the lakes. A more recent study in the Palisades Reservoir and Snake River in Idaho, USA, reported microplastics in $72 \%$ of the samples consisting mostly of films and fibres [65], suggesting a greater contribution from secondary sources.

In Asia, (Fig. 2; Online Resource 1) a study in Lake Hovsgol, Mongolia, reported average pelagic microplastic densities of 20,264 items per $\mathrm{km}^{2}$, despite its remoteness and low population density [35]. As microplastic abundance would be expected to be relatively lower in such

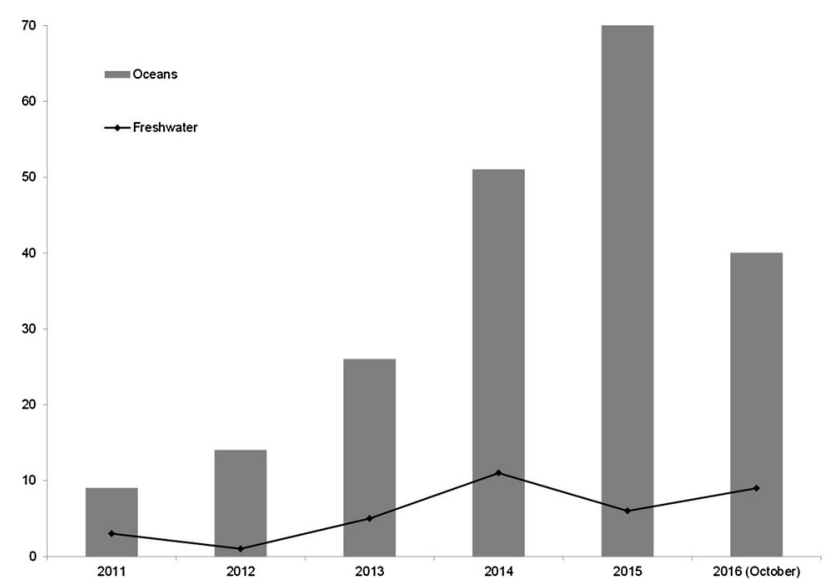

Fig. 1 Comparison of marine versus freshwater microplastics literature published between 2011 and September 2016, based on Web of Knowledge search engine accessed 3/10/2016 for search words: "microplastic + freshwater" and "microplastic + ocean" areas, this was attributed to the lake's long residence time, small surface area, and lack of proper waste management [35], indicating a strong need for effective control measures. Similarly, a more recent study of remote lakes in China found evidence of microplastics in abundances of $8 \pm 14$ to $563 \pm 1219$ items per $\mathrm{m}^{2}$ and attributed their presence to riverine inputs to the lakes and to a lesser extent atmospheric transport [99]. Data from remote areas are rarely generated but are important for understanding the ubiquity of these materials, as well as their transport pathways and fate. However, it remains necessary to consider developed areas with high industrial and anthropogenic activities. This is especially crucial in the Asian continent as the region contributes considerably to the global plastic production [77]. Marine data from the 1990s indicate that plastic litter in the Japanese coast increased by a factor of 10 every 2-3 years [75]. Further, microplastic pollution has been reported in coastlines of Japan [9] and Korea [53, 58] and in urban estuaries in China [100]. In this context, the region may present useful opportunities for studying these plastic particles in freshwaters that have highly populated and industrialised catchments, but the recent literature considering this is limited. In the Taihu Lake in China, microplastic abundances were highest in the most heavily contaminated areas of the lake, and abundances observed in plankton net samples were the highest reported worldwide, from $0.01 \times 10^{6}$ to $6.8 \times 10^{6}$ items per $\mathrm{km}^{2}$ [88].

The rest of the literature reviewed here between 2011 and 2016 comprises one study from Africa and several studies across Europe: Switzerland [31, 32], Italy [34, 50, 93], France [22], Germany [23, 55, 61, 94], Netherlands [7], Austria [57], and the UK [70]; (Fig. 2; Online Resource 1). In the African Great Lakes, suspected plastics were isolated from the gastrointestinal tracts of 55 and $35 \%$ of perch and tilapia samples, respectively [8]. While total abundances were not provided, and water or sediment samples were not examined, the study provides the first evidence of microplastic presence in inland waters in the African continent and the only one to date. Similarly to the African study, Switzerland and Italy surveys have focussed on lake systems, with microplastics reported in Lake Geneva [31, 32], the Lagoon in Venice [93], and Lakes Garda [50], Bolsena and Chiusi [34].

Most of the earlier freshwater research appears to have focussed on lentic systems (i.e. lakes), but rivers and WWT environments are gaining more attention as potential conduits of microplastics to the environment. A French study conducted in urban Paris sites was unique in being the first to quantify atmospheric fallout [22]. The same study also collected wastewater and surface water of urban rivers and reported a predominance of fibres across the different systems. In Germany, microplastics in the form of 


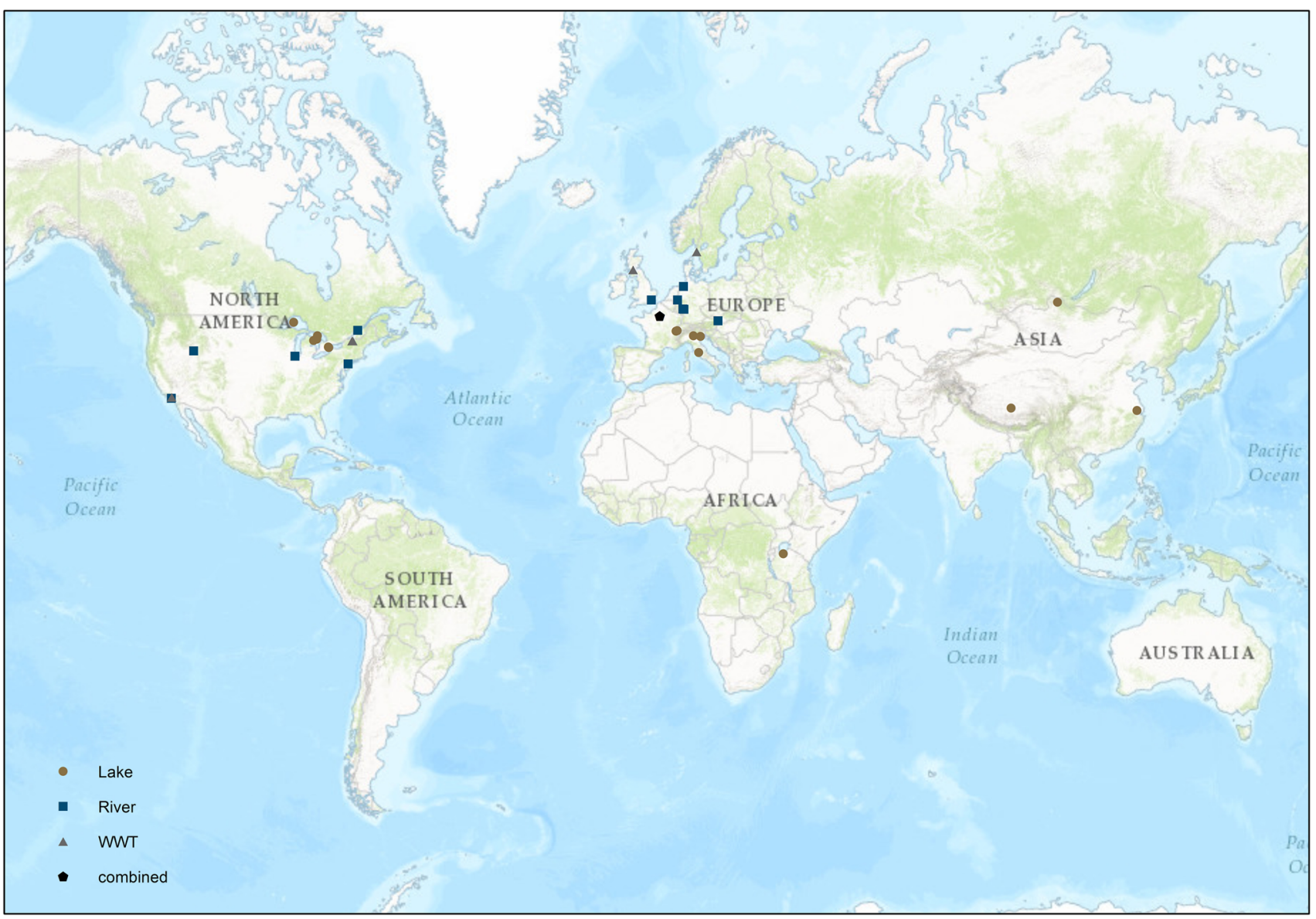

Fig. 2 Spatial distribution of microplastic studies conducted worldwide in freshwater and wastewater treatment (WWT) systems between 2011 and September $2016(n=34)$, according to system type (lake, river, WWT or a combination of two or more of these)

fragments, granules, and fibres were reported in all sediments of the Rivers Rhine, Elbe, Mosel, Neckar, and Main [55, 61, 94], and the Jade system of the southern North Sea [23]. Similarly, the studies conducted in Netherlands, Austria and the UK, also considered free-flowing waters from the Rivers Dommel [7], Danube [57], and Thames [70], respectively, and found evidence of microplastic pollution in all of them. Their findings support the consideration that these systems can be important transport routes but their distribution, retention and loading are largely influenced by a combination of in-stream processes and catchment characteristics.

\section{Rivers as Transport Pathways of MNP}

Rivers are dynamic systems that can either retain or transport MNP but quantitative evidence of river retention and discharge rates remains limited. It is considered that rivers can act as temporary sinks, delaying the release of microplastics to oceans, while transport of these materials can quickly increase during rain events due to increased flow rate $[37,64,79]$. In Brazil $[3,51]$ the presence of solid waste on beaches, including plastics, was attributed to domestic sources along the river basin, influenced by the proximity of river sources, and increased river flow during high rain events [79, 85]. Similarly, the Danube River was identified as an important transport route of plastics from production sites in Germany and Austria to the Black Sea, and it was proposed that variations in floating densities were linked to release of plastics from nearby production facilities [57]. In Chicago, higher MNP densities were observed after rain events during wet periods for two urban rivers, with evidence of higher abundances of primary MNP that are not regulated by total maximum daily loads (TMDLs) and being discharged into oceans [64]. However, export patterns are not always so clear. For example no major trends in particle sizes of larger plastic pieces (size categories not defined) was observed from up- to downstream sites in the Thames river, although generally higher abundances were observed in sites near sewage discharge [70]. The Tamar river in the UK was not determined to be a source of microplastics, despite their high abundance [85], considered to reflect drainage of a largely unpopulated catchment [24]. 


\section{Microplastics in Wastewater Treatment Systems}

The relationship between population density and urban and industrial activities with MNP presence in aquatic environments can be explored via analysis of wastewater effluent from treatment facilities and receiving waters. The WWT process may not completely remove MNP $[9,24,26,87]$, thus the role of each treatment stage in the degradation, generation, transport and removal of MNP, particularly those originating from primary sources, should be considered. Conversely, as the systems are expected to function properly in order to minimise treatment costs and ensure adequate water quality standards, the impact of MNP in the treatment process should also be evaluated.

There is increasing focus on considering the relationship between effluent discharge of MNP from wastewater treatment plants (WWTP) and MNP abundances in the recipient channel [22, 27, 48, 64]. Generally, higher microplastic concentrations were observed downstream of WWTP relative to upstream, based on observations in the North Shore Channel in Chicago $[48,64]$ and in the Raritan river in New Jersey [27], USA. However, no upstream to downstream evolution was observed in Urban sites in Paris [22].

Loadings from WWTP and the removal efficiency of various treatment stages has also been considered $[10,11,13,23,60,72]$. For example, in New York, discharges of 109,556, 81,911, and 1,061,953 particles per day were reported for three different WWTP [13], while an average annual discharge of $9 \times 10^{8}$ particles was reported from a WWTP in Germany [23]. In a smaller plant in Langeviksverket in Lysekil, Sweden, serving $\sim 12,000$ population equivalents, although most of the microplastics entering the WWTP were measured to be retained in the sewage sludge, the plant continued to discharge MNP, interpreted from higher concentrations in the recipient water compared to the reference site upstream [60]. Similarly, recent studies conducted in WWTP in Glasgow [72] and Southern California [11] observed that treatment was efficient in retaining microplastics via grit and grease removal (Glasgow) and skimming and settling processes (California). However, in both studies, secondary treatment plants continued to discharge microplastics at yields of 1 item per $1.14 \times 10^{3} \mathrm{~L}$ and $0.25+0.04$ items per $\mathrm{L}$ (equivalent to 65 million items a day) in the Glasgow and California studies, respectively. It is possible that larger WWTP will contribute larger MNP loads, and thus an additional treatment step before discharging effluent to receiving waters may help reduce its MNP concentrations. This projection is based on the observation of few to no microplastics in tertiary outflow of a WWTP in Southern California [11]. However, the general absence of quantitative studies considering removal at each stage of the treatment process makes this an area of high priority for further MNP research.

\section{Ecological Impacts}

The ecological effects of MNP in freshwater systems has received some scrutiny (see review by Eerkes-Medrano et al. [24]; however, this is limited. Owing to their small size, MNP can be ingested directly and indirectly by aquatic species more readily than larger particles, sometimes when mistaken for food, and leading to harmful physical effects [21]. Evidence from marine studies, for example, indicates that MNP ingestion may lead to choking, blocked digestive tracts, damage to organs, debilitation and ultimately death (see review by Derraik [21]). Similarities in MNP ingestion by freshwater organisms to marine fauna has been observed $[8,50,82,86]$ (see review by Eerkes-Medrano et al. [24]), but there is yet little evidence of uptake by fish and bird species in lakes [31, 32].

In addition, MNP can adsorb persistent organic pollutants (POPs), potentially introducing toxicity throughout the food web $[5,25,63,80]$, which could eventually reach humans by bioaccumulation [30]. Desorption of POPs and other manufacturing additives can increase pollutant concentrations in waters and increase the susceptibility of the larger pieces to degradation [23]. Nevertheless, information on sorption and leaching of POPs from microplastics is scarce [4], and most of the knowledge on toxicity derives from marine and laboratory experiments [24], while data from freshwaters remain limited. Further, MNP surfaces can provide habitats for microbial colonisation and biofilm formation, allowing for migration of opportunistic pathogens and invasive species [64, 98]. The latter may be relevant for WWTP as it could affect the functioning of the treatment processes, as well as increase the transport of WWT bacteria from these facilities to receiving waters [89, 98].

\section{Methods for Studying MNP}

Micro- and nanoplastic research is still a developing field, with as yet no standardised procedures for their study, and method advancement is still in its early stages [24, 89]. The different size class distinctions and methods used may reduce comparability of results across studies, highlighting the need to unify size class definition and develop simple, low-cost and precise methods for their detection and monitoring $[24,39]$. However, it may still be too early to do so, as we have yet to identify the spectrum, sizes, and 
types of MNP that require greater attention; thus for now, standardised procedures may prove useful only in situations that call for regular site-specific monitoring or have limited budgets $[24,35]$. Nevertheless, reviews of methods for identification and quantification of MNP in marine environments are available [47, 78], and the NOAA Marine Debris Program published a manual on recommended laboratory methods for quantifying plastics in oceanic waters and sediments [62]. The methods used for freshwater systems are similar to those implemented in marine studies.

The review of methods presented here is based on the generalised pathway used across studies (Fig. 3) and includes the techniques predominantly mentioned in the literature (Online Resource 1), tailored to gather information for quantification and characterisation of MNP, as well as describe their behaviour and fate in WWT and fluvial systems.

\section{Sampling and Processing}

Traditional sampling techniques for both surface water and sediments are common. Surface waters are often sampled

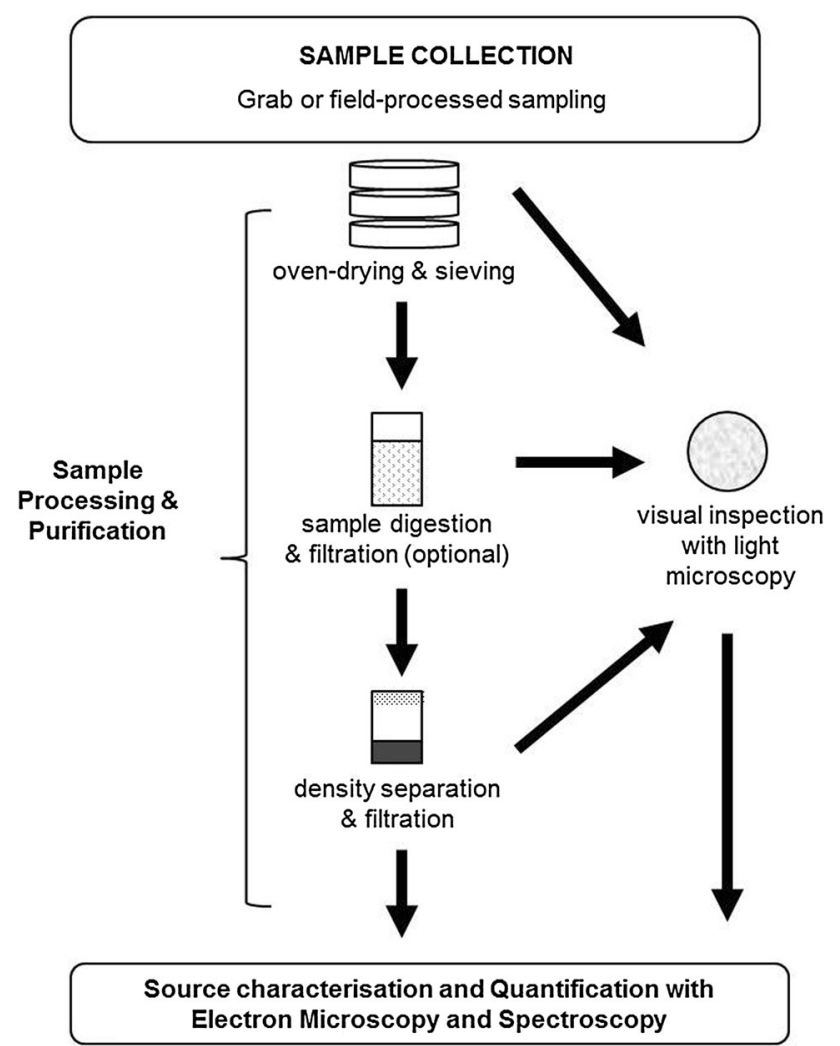

Fig. 3 Generalised pathway for extraction and identification of microplastics from sediment and water samples in freshwater systems, based on a review of different methods employed by various authors using manta trawls and neuston nets [47], while both in situ filtration and bulk sampling have been described for effluent discharge collection [9, 13, 47, 60, 72]. For lake sediments, selective sampling of visible pieces from beach transects was a frequent practice, and grab-sampling equipment (e.g. Ekman, Van Veen, Peterson and Ponar grabs) has been used for collection of lake-bottom sediments [12, 18, 47]. Shoreline sediment collection is generally accomplished through bulk sampling approaches such as steel trowels and box corers [34, 93, 96, 97].

Sample processing usually involves a combination of approaches including visual pre-selection, size fraction sieving, flotation and density separation, filtration and organic matter (OM) digestion [17, 47, 78, 89]. Sieve analysis is useful for separation of particles into different size ranges. A wide range of sieve sizes has been used across studies, and this approach will largely determine the minimum sizes of plastic debris that are collected and quantified [47]. For example, higher MNP abundances are usually reported where smaller mesh sizes were used in sieving and filtration [47, 87]. This is important as it may reduce the comparability and accuracy of results, possibly underestimating abundances in some cases from loss of material that is not retained in sieves and is discarded.

\section{Sample Purification}

After physical sorting by sieving, samples are purified using flotation and density separation of MNP from the organic and inorganic medium. Here too there is variation. Most commonly, sodium chloride $(\mathrm{NaCl})$ saturated solution is used for flotation of low-density particles from sediment [47]. Sodium iodide (NaI) and sodium polytungstate (SPT) have been used to float polymers with higher densities, although this approach tends to be more costly [14]. However, the approach is the same across studies: the sample is mixed with the solution, shaken for a certain amount of time and left to settle so that the lowerdensity particles rise to the surface. The floating pieces can be manually removed, and the smaller ones can be extracted by filtration of the supernatant through membrane filter [47]. The filtered samples are then either visually inspected for identification of microplastics, or further purified with acid, alkaline or enzymatic digestion methods.

Wet digestion protocols have been commonly employed to disintegrate biological materials and facilitate the extraction of microplastics from organic-rich media. Numerous methods are available for chemical removal of organic matter $(\mathrm{OM})$ [67] using different reagents such as $\mathrm{H}_{2} \mathrm{O}_{2}$ [81], $\mathrm{NaOCl}$ [1], $\mathrm{Na}_{2} \mathrm{~S}_{2} \mathrm{O}_{8}$ [66], $\mathrm{HNO}_{3}$ in combination with $\mathrm{H}_{2} \mathrm{O}_{2}$ [49] and $\mathrm{H}_{2} \mathrm{SO}_{4}$ [20]. Selection of the adequate protocol is largely dependent on reaction 
conditions and sample-specific properties, but protocols employing $\mathrm{H}_{2} \mathrm{O}_{2}$ remain more widely used. The efficiency of protocols for removing organic material, with minimum impact on composition of microplastic pieces, using $\mathrm{H}_{2} \mathrm{O}_{2}$ $[14,74], \mathrm{HNO}_{3}$ [14], $\mathrm{NaOH}[14,17,74], \mathrm{HCl}[17,74]$, $\mathrm{HNO}_{3}$ in combination with $\mathrm{HCl}$ or $\mathrm{H}_{2} \mathrm{O}_{2}$ [14], and enzymatic digestion [17], has been tested. The $\mathrm{HNO}_{3}, \mathrm{H}_{2} \mathrm{O}_{2}$ and Proteinase- $\mathrm{K}$ enzyme techniques exhibited high performance in disintegration of $\mathrm{OM}$, but their efficiencies seemed to rely largely on sample composition and reaction conditions (e.g., reagent concentration, temperature, and digestion time). For example, $\mathrm{HNO}_{3}$ removed more $\mathrm{OM}$ than $\mathrm{H}_{2} \mathrm{O}_{2}, \mathrm{NaOH}$, and in combination with other reagents [14], but these tests were performed on animal tissue only and direct digestion of PS spheres with $\mathrm{HNO}_{3}$ altered the composition of PS spheres. Conversely, the application of $35 \% \mathrm{H}_{2} \mathrm{O}_{2}$ digestion for seven days dissolved more organic debris than acids and alkalis, with minimal change to PP and PE particles [74]. However, biogenic material $<1 \mathrm{~mm}$ was not removed completely, and the remaining material was bleached, resulting in discolouration that could potentially interfere with visual identification of microplastics. The enzymatic digestion with Proteinase-K appears a rapid and efficient method to digest OM with ease, generating higher digestion efficacy $(>97 \%)$ than acid and alkaline digestion in plankton-rich samples and copepod tissue, with no visible impact to microplastics [17]. No tests have been conducted for OM removal efficiencies from wastewater or sludge samples using these approaches.

Alternative approaches for isolation of microplastics from sediment samples based on principles of elutriation (i.e. using a gas or liquid upward stream to separate particles) $[14,54]$ and pressurised fluid extraction [36] have been tested as a means to improve extraction efficiencies and showed promising results.

\section{Characterisation and Quantification}

After initial sorting and separation, suspected MNP are characterised and quantified for assessment of spatial and temporal distributions [47]. Typically, millimetre-sized particles are inspected initially under light microscopy, grouped according to different categories (e.g. type, shape, colour) and counted. Larger pieces are often counted with the naked eye or under a stereo microscope and identification of smaller pieces is commonly accomplished with the use of forensic techniques such as electron microscopy (EM) and spectroscopy techniques.

Electron microscopy provides further insight on the chemical and morphological characteristics of the plastic particles. There are two types of electron microscopy: scanning electron microscopy (SEM) and transmission electron microscopy (TEM). Typically, suspected MNPs are analysed with a SEM coupled with energy-dispersive $\mathrm{X}$-ray (EDS) microanalysis to produce backscatter electron (BSE) images and spectra for determination of elemental composition. These data can be used to discriminate carbon-based materials such as plastics from non-polymers as the plastics are made of $\mathrm{C}$ and so show $\mathrm{C}$-specific signals different than non-plastic materials. While SEM appears to be employed often [26, 48, 50, 64, 93, 96, 97], no studies reported using TEM.

Similarly, spectroscopic tools may be used for added analysis of individual particles, with Raman and Fourier Transform-Infra Red (FT-IR) spectroscopy used more frequently. These techniques are applied to gather information on polymer type, and the crystalline structure of the particles, which may provide insight into the sorption behaviour of persistent, bioaccumulating, and toxic substances, and the degradation of MNP from changes in bond distances [40]. Here, the basic principle is that infrared radiation is passed through a sample, where it is absorbed, reflected or transmitted. Although there are few differences between techniques, the end result is a molecular fingerprint represented by absorption and transmission, and as different materials will generate different spectra based on their unique molecular structures, the compound from which the MNP is derived can be identified [19]. This information may be used to trace sample origin and is crucial in understanding site-specific loadings. The FT-IR is gaining more popularity perhaps due to being non-destructive, less costly and easier to use, and involving little sample preparation [89].

Spectroscopy methods can be combined with microscopy to improve accuracy of the results. For example, the combined use of micro-FT-IR and molecular mapping by focal plane array (FPA) can help to reduce scanning time, and facilitate the analysis of entire membrane filters and smaller pieces without affecting spatial resolution [89, 93]. While the implementation of forensic techniques is becoming more common in more recent papers, these can be time-consuming and may not be accessible in every case. Therefore, use and selection of these approaches appears dependent largely on sample size and logistic constraints.

\section{Modelling of Transport}

Whilst every freshwater and wastewater survey conducted to date has reported microplastic occurrence in water and sediment samples, total and relative abundances are highly variable among studies and even within studies where different zones of a water body have been considered. While this may be attributed partly to differences in sampling, extraction, and identification techniques, site-specific characteristics (e.g. morphology, surface and catchment 
area, wind patterns; [34]) are likely to play an important role in MNP distribution and cycling in these systems. Higher abundances may be expected in habitats that accumulate smaller particles of sediment [9], and their distribution may be influenced by sediment transport and deposition processes [12, 55, 93]. Hydrodynamic effects can have greater influence in MNP distribution than population density, industrial activities, or sewage discharge and MNP concentrations in river shores, as observed in a case study in Germany [55]. As such, transport models can be useful tools to simulate MNP behaviour in riverine systems and evaluate the factors that control their transport and distribution; however, little focus has been given yet to investigate modelling approaches [73]. To examine riverine and wastewater inputs, sources and flow or discharge can be used as with other contaminants to predict MNP loading. In the Danube, plastic load at mean flow and a correction factor for population density were used to calculate plastic inputs to the Black Sea [57]. Flow rate data from two California rivers were also used to estimate yields of $>2$ billion particles over a $72 \mathrm{~h}$ period [69]. In Venice, high correlations were observed between small microplastics and fine grain size, indicating both follow similar sinking and accumulation processes, with higher accumulation of MNP in low energy sites [93].

Physical drivers for sediment transport can be tested to build models for MNP transport and storage, and identify areas of high deposition [73]. Fundamentally, if plastics behave in the same way as sediment, available hydraulic models can be easily applied to MNP load studies, and if they behave differently, the models can be fine-tuned to get their behaviour in properly. For example, use of a modified INCA-Contaminants simulator, utilising catchment hydrology, soil erosion and metereological controls for prediction of microplastic accumulation and distribution, revealed strong hydrolological controls in transport and storage of microplastics [73]. Heavier and larger microplastics $(>2.0 \mathrm{~mm})$ were more likely to be retained in hotspots for sediment deposition, but high flow events caused their remobilisation [73]. A similar approach can be used with other available models, for example the Delft hydraulics model (Delft 3D suite) for rivers and estuaries. This model allows particle tracking and has a morphology module that predicts sediment movement (Deltares, https://oss.deltares.nl/ web/delft3d/about). Statistical approaches could explore linkage between model parameters, e.g. the relationship between grain and MNP size classes, and later incorporated into the transport model to project loading of MNP from freshwaters systems. Further research should focus on modelling approaches as a tool to predict MNP fate in the environment and further understanding of the inheritance of terrestrial MNPs to oceans.

\section{Conclusions}

This analysis contributes to recent freshwater and methodology reviews [24, 47, 78] by widening the ongoing discussion to include the more recent publications, WWT surveys, and additional methodological approaches that can generate incisive understanding of key aspects of MNP pollution in these systems.

Micro- and nanoplastic fragments originating from primary or secondary sources are contaminants of emerging concern $[42,46]$. Considerable work undertaken in recent years advances knowledge of MNP contamination of aquatic environments, but several key challenges remain in this new field of water research. With the majority of surveys to date focussing on marine systems, further research should aim to expand spatial coverage of MNP studies, especially for continental waters, and consider the role of free-flowing freshwaters as transport vectors of land-based inputs to oceans, especially those receiving discharges from WWTP. A few WWT studies are available, but these systems remain largely understudied, providing an area for further investigation. Further, studies conducted in WWT systems should consider not only the removal of MNP by treatment processes, but also the impact of these contaminants on the efficacy of the treatment plant, and their potential for picking up and transporting substances and bacteria that may jeopardise water quality in the recipient channel.

Owing to their small sizes and a lack of unified methods, adequate quantitative and qualitative analysis and reliable risk assessment of MNP have been difficult [46], especially in the case of nanoplastics, which are yet to be isolated from environmental samples. A unification of methodology for improved quantitative and qualitative assessment of the microplastic fractions could provide guidance for examination of nanoplastic fractions, which are believed to increase in importance as an ecological threat in coming years [43]. While a wide array of protocols have been tested for MNP evaluation, method development research should consider using sample purification and forensic techniques in combination rather than individually, and aim to unify size class definitions and units of measurement to improve comparability among studies. In fluvial systems, modelling tools can be useful to assess key aspects regarding transport, degradation, storage, and fate of MNP in the environment. These considerations will result in a more accurate assessment of MNP abundance and distribution, both in inland and oceanic waters, helping to reduce errors in reporting results, and contributing to identification of where control measures should be implemented.

Acknowledgements This project is funded by the Scottish Government's Hydro Nation Scholars Programme. The programme is 
supported by CREW (Scotland's Centre of Expertise for Waters) and administered by the James Hutton Institute.

\section{Compliance with Ethical Standards}

Conflict of interest The authors declare that they have no conflict of interest.

Open Access This article is distributed under the terms of the Creative Commons Attribution 4.0 International License (http://crea tivecommons.org/licenses/by/4.0/), which permits unrestricted use, distribution, and reproduction in any medium, provided you give appropriate credit to the original author(s) and the source, provide a link to the Creative Commons license, and indicate if changes were made.

\section{References}

1. Anderson JU (1963) An improved pretreatment for mineralogical analysis of samples containing organic matter. Clay Miner 10:380-388

2. Andrady AL (2011) Microplastics in the marine environment. Mar Pollut Bull 62:1596-1605

3. Araújo MC, Costa M (2007) An analysis of the riverine contribution to the solid wastes contamination of an isolated beach at the Brazilian Northeast. Manag Environ Qual Int J 18:6-12

4. Arthur C, Baker J, Bamford H (2009) Proceedings of the International Research Workshop on the Occurrence, Effects and Fate of Micro-plastic Marine Debris, Sept 9-11, 2008. NOAA Technical Memorandum NOS-OR\&R-30

5. Bakir A, Rowland SJ, Thompson RC (2012) Competitive sorption of persistent organic pollutants onto microplastics in the marine environment. Mar Pollut Bull 64:2782-2789

6. Ballent A, Corcoran PL, Madden O, Helm PA, Longstaffe FJ (2016) Sources and sinks of microplastics in Canadian Lake Ontario nearshore, tributary and beach sediments. Mar Pollut Bull 110:383-395

7. Besseling E, Quik JTK, Koelmans AA (2014) Modeling the fate of nano- and microplastics in freshwater systems. In: Abstract book 24th Annual meeting SETAC Europe: science across bridges, borders and boundaries. http://library.wur.nl/WebQu ery/wurpubs/479772. Accessed 1 Nov 2015

8. Biginagwa FJ, Mayoma BS, Shashoua Y, Syberg K, Khan FR (2015) First evidence of microplastics in the African Great Lakes: recovery from Lake Victoria Nile perch and Nile tilapia. J Great Lakes Res 42:146-149

9. Browne MA, Crump P, Niven SJ, Teuten E, Tonkin A, Galloway T, Thompson R (2011) Accumulation of microplastic on shorelines worldwide: sources and sinks. Environ Sci Technol 45:9175-9179

10. Buksa B, Niekrewicz T (2016) Microplastic pollution: a survey of wastewater effluent in Plattsburgh, NY. Center for Earth and Environmental Science Student Posters. Book 26. http://digi talcommons.plattsburgh.edu/cees_student_posters/26/. Accessed 3 Oct 2016

11. Carr S, Liu J, Tesoro AG (2016) Transport and fate of microplastic particles in wastewater treatment plants. Water Res 91:174-182

12. Castañeda RA, Avlijas S, Simard MA, Ricciardi A (2014) Microplastic pollution in St. Lawrence River sediments. Can J Fish Aquat Sci 71:1767-1771

13. Chaskey E, Hirsch T, Drake T, Ehmann K, Chu Y (2014) Microplastic pollution: a comparative survey of wastewater effluent in
New York. Center for Earth and Environmental Science Student Posters. Book 8. http://digitalcommons.plattsburgh.edu/cees_ student_posters/8. Accessed 1 Nov 2015

14. Claessens M, van Cauwenberghe L, Vandegehuchte MB, Janssen CR (2013) New techniques for the detection of microplastics in sediments and field collected organisms. Mar Pollut Bull 70:227-233

15. Coe J, Rogers D (1997) Marine debris: sources, impacts and solutions. Springer, New York

16. Cole M, Lindeque P, Halsband C, Galloway TS (2011) Microplastics as contaminants in the marine environment: a review. Mar Pollut Bull 62:2588-2597

17. Cole M, Webb H, Lindeque PK, Fileman ES, Halsband C, Galloway TS (2014) Isolation of microplastics in biota-rich seawater samples and marine organisms. Sci Rep 4:4528

18. Corcoran PL, Norris T, Ceccanese T, Walzak MJ, Helm PA, Marvin CH (2015) Hidden plastics of Lake Ontario, Canada and their potential preservation in the sediment record. Environ Pollut 204:17-25

19. Das RS, Agrawal YK (2011) Raman spectroscopy: recent advancements, techniques and applications. Vib Spectrosc $57: 163-176$

20. Dean JA (1999) Lange's handbook of chemistry, 15th edn. McGraw-Hill, New York

21. Derraik JG (2002) The pollution of the marine environment by plastic debris: a review. Mar Pollut Bull 44:842-852

22. Dris R, Gasperi J, Rocher V, Saad M, Renault N, Tassin B (2015) Microplastic contamination in an urban area: a case study in Greater Paris. Environ Chem 12:592-599

23. Dubaish F, Liebezeit G (2013) Suspended microplastics and black carbon particles in the Jade system, southern North Sea. Water Air Soil Pollut 224:1-8

24. Eerkes-Medrano D, Thompson RC, Aldridge DC (2015) Microplastics in freshwater systems: a review of the emerging threats, identification of knowledge gaps and prioritisation of research needs. Water Res 75:63-82

25. Endo S, Takizawa R, Okuda K, Takada H, Chiba K, Kanehiro H, Date T (2005) Concentration of polychlorinated biphenyls (PCBs) in beached resin pellets: variability among individual particles and regional differences. Mar Pollut Bull 50:1103-1114

26. Eriksen M, Mason S, Wilson S, Box C, Zellers A, Edwards W, Amato S (2013) Microplastic pollution in the surface waters of the Laurentian Great Lakes. Mar Pollut Bull 77:177-182

27. Estahbanati S, Fahrenfeld NL (2016) Influence of wastewater treatment plant discharges on microplastic concentrations in surface water. Chemosphere 162:277-284

28. European Commission (2011) Plastic waste: ecological and human health impacts. Science for environment policy: in-depth reports

29. European Commission DG Environment (2011) Plastic waste in the environment-final report

30. Farrel P, Nelson K (2013) Trophic level transfer of microplastic: Mytilus edulis (L.) to Carcinus maenas (L.). Environ Pollut 177:1-3

31. Faure F, Corbaz M, Baecher H, de Alencastro L (2012) Pollution due to plastics and microplastics in Lake Geneva and in the Mediterranean Sea. Arch Sci 65:157-164

32. Faure F, Demars C, Wieser O, Kunz M, de Alencastro L (2015) Plastic pollution in Swiss surface waters: nature and concentrations, interaction with pollutants. Environ Chem 12:582-591

33. Fendall LS, Sewell MA (2009) Contributing to marine pollution by washing your face: microplastics in facial cleansers. Mar Pollut Bull 58:1225-1228

34. Fischer EK, Paglialonga L, Czech E, Tamminga M (2016) Microplastic pollution in lakes and lake shoreline sediments-a 
case study on Lake Bolsena and Lake Chiusi (central Italy). Environ Pollut 213:648-657

35. Free CM, Jensen OP, Mason SA, Eriksen M, Williamson NJ, Boldgiv B (2014) High-levels of microplastic pollution in a large, remote, mountain lake. Mar Pollut Bull 85:156-163

36. Fuller S, Gautam A (2016) A procedure for measuring microplastics using pressurized fluid extraction. Environ Sci Technol 50:5774-5780

37. Galgani F, Leauté JP, Moguedet P, Souplet A, Verin Y, Carpentier A, Goraguer H, Latrouite D, Andral B, Cadiou Y, Mahe JC, Poulard JC, Nerisson P (2000) Litter on the sea floor along European coasts. Mar Pollut Bull 40:516-527

38. Galgani F, Hanke G, Werner S, Piha H (2011) MSFD GES technical subgroup on marine litter. Technical recommendations for the implementation of MSFD requirements. JRC Scientific and Technical Report, EUR, 25009, 93

39. Galgani F, Hanke G, Werner S, De Vrees L (2013) Marine litter within the European Marine Strategy Framework Directive. ICES J Mar Sci 70:1055-1064

40. Gerrard DL, Maddam WF (1986) Polymer characterization by Raman spectroscopy. Appl Spectrosc Rev 22:251-334

41. GESAMP (Joint Group of Experts on the Scientific Aspects of Marine Environmental Protection) (1991) The state of the marine environment. Blackwell Scientific Publications, London, p 146

42. GESAMP (Joint Group of Experts on the Scientific Aspects of Marine Environmental Protection) (2015) Sources, fate and effects of microplastics in the marine environment: a global assessment. In: Kershaw PJ (ed.) IMO/FAO/UNESCO-IOC/ UNIDO/WMO/IAEA/UN/UNEP/UNDP Rep. Stud. GESAMP No. 90

43. Gigault J, Pedrono B, Maxit B, Ter Halle A (2016) Marine plastic litter: the unanalysed nano-fraction. Environ Sci Nano 3:346-350

44. Gordon M (2006) Eliminating land-based discharges of marine debris in California: a plan of action. Plastic debris rivers to sea project, Algalita Marine Research Foundation, California Coastal Commission

45. Gregory MR, Andrady AL (2003) Plastics in the marine environment. In: Andrady AL (ed) Plastics and the Environment. John Wiley and Sons, Hoboken, NJ, pp 379-401

46. Hartl MGJ, Gubbins E, Gutierrez T, Fernandes TF (2015) Review of existing knowledge-emerging contaminants: focus on nanomaterials and microplastics. CREW-Centre of Expertise for Waters

47. Hidalgo-Ruz V, Gutow L, Thompson RC, Thiel M (2012) Microplastics in the marine environment: a review of the methods used for identification and quantification. Environ Sci Technol 46:3060-3075

48. Hoellein TJ, McCormick A, Kelly JJ (2014) Riverine microplastic: abundance and bacterial community colonization. Abstract. Joint Aquatic Sciences Meeting. Portland

49. Huang CYL, Schulte EE (1985) Digestion of plant tissue for analysis by ICP emission spectroscopy. Commun Soil Sci Plant Anal 16:943-985

50. Imhof HK, Ivleva NP, Schmid J, Niessner R, Laforsch C (2013) Contamination of beach sediments of a subalpine lake with microplastic particles. Curr Biol 23:867-868

51. Ivar do Sul JA, Costa MF (2013) Plastic pollution risks in an estuarine conservation unit. In: Conley DC, Masselink G, Russell PE, O'Hare TJ (eds) Proceedings from the 12th International Coastal Symposium (Plymouth, England), Journal of Coastal Research, Special Issue No. 65, 2013, pp 48-53

52. Jeftic L, Sheavly SB, Adler E (2009) Marine litter: a global challenge. In: Meith N (ed) Regional Seas, United Nations Environment Programme
53. Kang JH, Kwon OY, Lee KW, Song YK, Shim WJ (2015) Marine neustonic microplastics around the southeastern coast of Korea. Mar Pollut Bull 96:304-312

54. Kedzierski M, Le Tilly V, Bourseau P, Bellegou H, César G, Sire O, Bruzaud S (2016) Microplastics elutriation from sandy sediments: a granulometric approach. Mar Pollut Bull 107:315-323

55. Klein S, Worch E, Knepper TP (2015) Occurrence and spatial distribution of microplastics in river shore sediments of the Rhine-Main area in Germany. Environ Sci Technol 19:6070-6076

56. Koelmans AA, Besseling E, Shim WJ (2015) Nanoplastics in the aquatic environment. In: Bergmann M, Gutow L, Klages M (eds) Marine anthropogenic litter. Springer, Berlin, pp 325-342

57. Lechner A, Keckeis H, Lumesberger-Loisl F, Zens B, Krusch R, Tritthart M, Schludermann E (2014) The Danube so colourful: a potpourri of plastic litter outnumbers fish larvae in Europe's second largest river. Environ Pollut 188:177-181

58. Lee J, Hong S, Song YK, Hong SH, Jang YC, Jang M, Shim WJ (2013) Relationships among the abundances of plastic debris in different size classes on beaches in South Korea. Mar Pollut Bull 77:349-354

59. Lee J, Lee JS, Jang YC, Hong SY, Shim WJ, Song YK, Hong SH, Jang M, Han GM, Kang D, Hong S (2015) Distribution and size relationships of plastic marine debris on beaches in South Korea. Arch Environ Contam Toxicol 69:288-298

60. Magnusson K, Norén F (2014) Screening of microplastic particles in and down-stream a wastewater treatment plant. Technical Report published for IVL Swedish Environmental Research Institute, August 2014; Swedish Environmental Research Institute: Stockholm, Sweden

61. Mani T, Hauk A, Walter U, Burkhardt-Holm P (2015) Microplastics profile along the Rhine River. Sci Rep 5:1-7

62. Masura J, Baker J, Foster G, Arthur C (2015) Laboratory methods for the analysis of microplastics in the marine environment: recommendations for quantifying synthetic particles in waters and sediments. NOAA Technical Memorandum NOSOR\&R-48

63. Mato Y, Isobe T, Takada H, Kanehiro H, Ohtake C, Kaminuma $\mathrm{T}$ (2001) Plastic resin pellets as a transport medium for toxic chemicals in the marine environment. Environ Sci Technol $35: 318-324$

64. McCormick A, Hoellein TJ, Mason SA, Schluep J, Kelly JJ (2014) Microplastic is an abundant and distinct microbial habitat in an urban river. Environ Sci Technol 48:11863-11871

65. McDevitt C, Perez L, Kapp K (2016) The presence of microplastic in freshwater systems: snake river and palisades reservoir. http://repository.uwyo.edu/ugrd/2015_UGRD/Sche dule/163/. Accessed 3 Oct 2016

66. Meier LP, Megenatti AP (1997) A new, efficient, one-step method for the removal of organic matter from clay-containing sediments. Clay Miner 32:557-563

67. Mikutta R, Kleber M, Kaiser K, Jahn R (2005) Review: organic matter removal from soils using hydrogen peroxide, sodium hypochlorite, and disodium peroxodisulfate. Soil Sci Soc Am J 69:120-135

68. Moore CJ, Moore SL, Leecaster MK, Weisberg SB (2001) A comparison of plastic and plankton in the North Pacific central gyre. Mar Pollut Bull 40:83-88

69. Moore CJ, Lattin GL, Zellers AF (2011) Quantity and type of plastic debris flowing from two urban rivers to coastal waters and beaches of Southern California. J Integr Coast Zone Manag 11:65-73

70. Morritt D, Stefanoudis PV, Pearce D, Crimmen OA, Clark PF (2014) Plastic in the Thames: a river runs through it. Mar Pollut Bull 78:196-200 
71. MSFD Technical Subgroup on Marine Litter (2013) Monitoring guidance for marine litter in European Seas, Draft report. European Commission, Brussels

72. Murphy F, Ewins C, Carbonnier F, Quinn B (2016) Wastewater treatment works as a source of microplastics in the aquatic environment. Environ Sci Technol 50:5800-5808

73. Nizzetoo L, Bussi G, Futter MN, Butterfield D, Whitehead PG (2016) A theoretical assessment of microplastic transport in river catchments and their retention by soils and river sediments. Environ Sci Process Impacts 18:1050-1059

74. Nuelle MT, Dekiff JH, Remy D, Fries E (2014) A new analytical approach for monitoring microplastics in marine sediments. Environ Pollut 184:161-169

75. Ogi H, Fukamoto Y (2000) A sorting method for small plastic debris floating on the sea surface and stranded on sandy beaches. Bull Fac Fish 51:71-93

76. Pinto da Costa J, Santos PSM, Duarte AC, Rocha-Santos T (2016) (Nano)plastics in the environment-sources, fates and effects. Sci Total Environ 566-567:15-26

77. Plastics Europe (2015) Plastics - the facts 2014/2015. An analysis of European plastics production, demand and waste data (Plastics Europe, Brussels)

78. Qiu Q, Tan Z, Wang J, Peng J, Li M, Zhan Z (2016) Extraction, enumeration and identification methods for monitoring microplastics in the environment. Estuar Coast Shelf $\mathrm{S}$ 176:102-109

79. Rech S, Macaya-Caquilpán V, Pantoja JF, Rivadeneira MM, Madariaga DJ, Thiel M (2014) Rivers as a source of marine litter-a study from the SE Pacific. Mar Pollut Bull 82:66-75

80. Rios Mendoza LM, Evans CY (2013) Plastics are invading not only the ocean but also the Great Lakes. In: Abstracts of papers of the American Chemical Society, vol. 245

81. Robinson GW (1927) The determination of organic matter in soils by hydrogen peroxide. J Agric Res 34:339-356

82. Rochman CM, Hoh E, Kurobe T, Teh SJ (2013) Ingested plastic transfers hazardous chemicals to fish and induces hepatic stress. Sci Rep 3:3263

83. Roex E, Vethaak D, Leslie H, Kreuk MD (2013) Potential risk of microplastics in the fresh water environment. STOWA, Amersfoort

84. Ryan PG, Moore CJ, van Franeker JA, Moloney CL (2009) Monitoring the abundance of plastic debris in the marine environment. Philos Trans R Soc B 364:1999-2012

85. Sadri SS, Thompson RC (2014) On the quantity and composition of floating plastic debris entering and leaving the Tamar Estuary, Southwest England. Mar Pollut Bull 81:55-60

86. Sanchez W, Bender C, Porcher JM (2014) Wild gudgeons (Gobio gobio) from French rivers are contaminated by microplastics: preliminary study and first evidence. Environ Res 128:98-100

87. Storck FR, Karlsruhe TZW, Kools SA (2015) Microplastics in fresh water resources

88. Su L, Xue Y, Li L, Yang D, Kolandhasamy P, Li D, Shi H (2016) Microplastics in Taihu Lake, China. Environ Pollut 2016:711-719

89. Tagg AS, Sapp M, Harrison JP, Ojeda JJ (2015) Identification and quantification of microplastics in wastewater using FPAbased reflectance micro-FT-IR imaging. Anal Chem 87:6032-6040

90. Thompson RC (2006) Plastic debris in the marine environment: consequences and solutions. Mar Nat Conserv Eur 193:107

91. Thompson RC, Olsen Y, Mitchell RP, Davis A, Rowland SJ, John AWG, McGonigle D, Russell AE (2004) Lost at sea: where is all the plastic? Science 304:838

92. Thompson RC, Swan SH, Moore CJ, vom Saal FS (2009) Our plastic age. Philos Trans R Soc London, Ser B Biol Sci 364:1973-1976

93. Vianello A, Boldrin A, Guerriero P, Moschino V, Rella R, Sturaro A, Da Ros L (2013) Microplastic particles in sediments of Lagoon of Venice, Italy: first observations on occurrence, spatial patterns and identification. Estuar Coast Shelf Sci 130:54-61

94. Wagner M, Scherer C, Alvarez-Muñoz D, Brennholt N, Bourrain X, Buchinger S, Reifferscheid G (2014) Microplastics in freshwater ecosystems: what we know and what we need to know. Environ Sci Eur 26:1-9

95. Williams AT, Simmons SL (1996) The degradation of plastic litter in rivers: implications for beaches. J Coast Conserv 2:63-72

96. Zbyszewski M, Corcoran PL (2011) Distribution and degradation of fresh water plastic particles along the beaches of Lake Huron, Canada. Water Air Soil Pollut 220:365-372

97. Zbyszewski M, Corcoran PL, Hockin A (2014) Comparison of the distribution and degradation of plastic debris along shorelines of the Great Lakes, North America. J Great Lakes Res 40:288-299

98. Zettler ER, Mincer TJ, Amaral-Zettler LA (2013) Life in the "plastisphere": microbial communities on plastic marine debris. Environ Sci Technol 47:7137-7146

99. Zhang K, Su J, Xiong X, Wu X, Wu C, Liu J (2016) Microplastic pollution of lakeshore sediments from remote lakes in Tibet plateau, China. Environ Pollut 219:450-455

100. Zhao S, Zhu L, Li D (2015) Microplastic in three urban estuaries, China. Environ Pollut 206:597-604 